\title{
The Effects of Takeover Threats on Shareholders and Firm Value
}

\author{
Marco Haan* Yohanes Riyanto
}

February 24, 2000

\begin{abstract}
We study the role of takeover threats as a corporate control mechanism using Aghion and Tirole's (1997) model of formal and real authority. Shareholders do not monitor the manager's actions, since ownership is widely dispersed. A corporate raider may monitor, and steps in if a profit opportunity exists. In our model, a takeover threat decreases the manager's effort and harms shareholders. The effect of a takeover threat on the expected value of the firm is ambiguous. It is in the interest of the corporate raider if severance payments the manager receives upon being fired are high. Shareholders, however, prefer them to be low.
\end{abstract}

JEL Classification Codes: G34, G35, G38.

* Department of Economics, Micro-economics, University of Groningen, P.O. Box 800, 9700 AV Groningen, The Netherlands. Phone: +31-50-3637327. Fax: +31-50-3637337. e-mail: m.a.haan@eco.rug.nl.

Center for Economic Studies, Katholieke Universiteit Leuven, Naamsestraat 69, B-3000 Leuven, Belgium. Phone: +32-16-326831, Fax: +32-16-326796, e-mail: Yohanes.Riyanto@econ.kuleuven.ac.be. The authors thank Elazar Berkovitch, Arnoud Boot, Christa Bouwman, Hans Degryse, Mathias Dewatripont, Dave Furth, Denis Gromb, Ulrich Hege, Mark Helmantel, Thijs Knaap, Inés Macho-Stadler, David Pérez-Castrillo, Bert Schoonbeek, Armin Schwienbacher, Sudhir Sudarsanam, Matti Suominen, seminar participants at the University of Amsterdam, the University of Groningen, CENTER, and Boston University, and conference participants at EARIE 1999, EEA 1999, and EFA 1999 for useful comments. The latest version of this paper can be found on http://www.eco.rug.nl/medewerk/haanma 


\section{Introduction}

In many corporations the owners are rarely those who control the day-to-day operation. This separation of ownership and control can give rise to agency problems. A manager may have an incentive to pursue his own interests at the expense of the owners. The owners can alleviate this problem by monitoring his actions. Yet, when ownership is widely dispersed, and monitoring is costly, no shareholder has an incentive to do so. Alternatively, an outside raider can monitor the actions of the manager. If she ${ }^{1}$ feels that he does not maximize the value of the firm, she can choose to take control, and overrule the manager. In this paper, we study the effects of such a takeover threat on the actions of the manager, the value of the shares, and the value of the firm.

In the agency literature, it is usually assumed that if a principal increases her monitoring effort, the agent will increase his effort as well. ${ }^{2}$ Stronger monitoring increases the probability of being caught shirking, hence the incentive to shirk decreases. In a recent paper, however, Aghion and Tirole (1997) argue that the opposite may also be true. Suppose that an agent can take initiatives, and derives private benefits from doing so. Then, stronger monitoring implies a higher probability that the agent is overruled by the principal. This lowers the agent's incentive to take initiatives, which may hurt the principal as well. In that framework, effort levels of the principal and agent are strategic substitutes ${ }^{3}$, rather than strategic complements, as they are in the standard agency literature.

This set-up seems especially relevant to analyze the relationship between managers and shareholders. Managers are usually expected to take initiatives and look for new opportunities, rather than being passive and perform some pre-defined tasks. Managers also obtain some private benefits from taking these initiatives, such as status, prestige, perquisites, satisfaction from performing certain tasks, and possible side-payments. Giving managers the freedom to take initiatives may be desirable if the projects preferred by them also yield higher profits to the firm's shareholders. However, a complication may arise when the interests of managers are not fully aligned with the interests of shareholders. In that case, shareholders will impose a certain degree of control upon managers.

Burkart, Gromb, and Panunzi (1997) use the framework of Aghion and Tirole (1997) to study the role of direct shareholder monitoring. They show that for a large shareholder,

\footnotetext{
1 In the remainder of this paper, we will refer to the manager as being male, and to the raider as being female.

2 See for example Shapiro and Stiglitz (1987).

3 See Bulow, Geneakoplos and Klemperer (1985).
} 
the incentive to monitor is increasing in $\alpha$, the fraction of shares she owns. However, there is a trade-off between costs and benefits of monitoring. Too much monitoring will destroy managerial initiatives. Too little monitoring, however, will give too much discretionary power to managers. Therefore, the optimal ownership structure is characterized by some intermediate value of $\alpha$. The authors thus show that $\alpha$ can be used as a commitment device.

Burkart, Gromb, and Panunzi (1997) only study one particular corporate control mechanism. Their model requires that there is a large shareholder who monitors the manager. Therefore, the model is appropriate for analyzing a corporate governance system which relies on the role of monitoring by a large shareholder. Such a system exists in Continental Europe and Japan. In Anglo-Saxon countries, however, the corporate governance structure is characterized by the presence of many small shareholders (See e.g. Shleifer and Vishny 1997). In such a system the role of direct shareholder monitoring is much less significant. In the absence of direct monitoring, takeover threats are often used as a corporate control mechanism. (See also Hart 1995).

In this paper we use the Aghion and Tirole (1997) framework to study the role of takeover threats as a corporate control mechanism. Our analysis is complementary to that of Burkart, Gromb and Panunzi (1997). We assume that there are many small shareholders who do not directly monitor the manager because of a free-rider problem. The manager has full discretionary power to decide which project should be undertaken. The choice of project depends on the size of private benefits that he obtains. Following Aghion and Tirole (1997), we assume that the manager's most preferred project also yields positive profits for shareholders. Yet, a different project exists that yields higher shareholder value. A raider may investigate the possibility of a takeover. She will step in if there is a profit opportunity, which is the case if the project chosen by the manager diverges sufficiently from the project that is optimal from the point of view of the shareholders. If the raider takes over the firm, she pays some fixed premium for the shares, and implements her optimal project.

We obtain the following results. First, we show that, due to a takeover threat, the effort exerted by the manager will decrease. It is usually argued that a takeover threat will discipline the manager, and increase his effort (see for example Scharfstein 1988). Yet, in our model, a takeover threat introduces the possibility that the manager will be overruled. If he is overruled, the effort he has taken in evaluating different projects, will be wasted. Therefore, a takeover threat reduces the incentive to take such efforts in the first place. This effect is similar to that described in Kahn and Huberman (1988). In their model, employees who face the possibility of being fired, have less incentive to invest in firm-specific human capital. In Shleifer and Summers (1988), takeovers are a mechanism to break the implicit contract between managers 
and workers. Therefore, workers are less inclined to engage in such contracts in the first place. Due to a takeover threat, the workers may then be reluctant to invest in relationship-specific human capital. In our paper, a takeover threat makes managers more reluctant to invest in relationship-specific information. The mechanism, however, is fundamentally different from Shleifer and Summers (1988).

Second, we show that shareholders prefer not to have a takeover threat. Note that a takeover threat has two effects. On the one hand, if there is a takeover, shareholders earn more, since they receive more for their shares than they would in the absence of a takeover. On the other hand, as we saw above, the effort of the manager is lower with a takeover threat, which reduces shareholder value. In our model, the second effect dominates.

Our third result is that the effect of a takeover on the expected ex post value of the firm is ambiguous. Again, there are two counterveiling effects. On the one hand, if there is a takeover, the raider will implement a project that yields higher firm value. On the other hand, the takeover threat reduces the manager's effort. The net effect is ambiguous. Suppose society's aim is to maximize the expected value of the firm. Then these results imply that the interests of society are not necessarily aligned with those of the shareholders. It is always in the interest of shareholders not to have a takeover threat. Yet, not having a takeover threat does not always maximize the expected value of the firm.

Finally, we show that the utility the manager obtains when a takeover occurs, influences the likelihood of a takeover threat. High severance payments to the manager in the event of a takeover will increase the likelihood of a takeover. This result is in contrast to the argument that a golden parachute helps to align the interests of the manager and shareholders, as argued by e.g. Knoeber (1986). The intuition behind our result is the following. If the manager's utility is very low in case of a takeover, he will be inclined to try to avoid such a takeover from occurring. He can do so by implementing the project that is in the best interest of the shareholders, rather than the one that is in his own best interest. If he does so, a takeover can never be successful, since a raider cannot increase the value of the firm. But that implies that the raider prefers a situation in which the manager is paid handsomely should a takeover occur. Only in that case the manager will be inclined to follow his own interest rather than that of the shareholders. This is a necessary condition for a takeover to be successful. Obviously, shareholders have the opposite interest. They prefer the case in which the manager's utility is very low if a takeover occurs.

This paper is organized as follows. In section 2 we present the monitoring technology used in this paper, which is based on Aghion and Tirole (1997). Section 3 studies the benchmark model with dispersed ownership and no takeover threat, and in section 4 
we study the case where a takeover threat is present. Section 5 derives the necessary conditions for a takeover threat to be present, which allows us to describe the full model in section 6 . The properties of the model are analyzed in section 7, while section 8 studies the effect of a change in the exogenous parameters of our model. Section 9 concludes.

\section{The Monitoring Technology}

In this section we outline the monitoring technology used in this model, which is based on Aghion and Tirole (1997). Consider an agent who is supervised by a principal. Later, we will interpret the agent as the manager, and the principal as either the shareholders or the corporate raider. The agent can undertake one of $N+1$ possible projects. Project $i$, with $i \in\{0,1,2, \ldots, N\}$, yields benefits $b^{i}$ to the agent, and benefits $\Pi^{i}$ to the principal. These benefits are nonverifiable ex-ante. Hence, a contract between principal and agent cannot be written based on these. Project 0 yields benefits to both parties that are normalized to zero: $b^{0}=\Pi^{0}=0$. This is known to both the principal and the agent. However, they do not know the payoffs of the other $N$ projects. When any of the $N$ projects is picked at random, the expected payoff to both parties is negative. Hence, when both are uninformed, they prefer to implement project 0 .

By exerting effort, the agent can learn the payoffs of all projects, with a probability that is increasing in his effort. Specifically, he can exert non-verifiable effort $e \in$ $[0,1]$. The private costs of doing so equal $e^{2} / 2$, and by exerting that effort he learns the payoffs of all projects with probability $e$. The principal can also invest in information acquisition. She can exert effort $E \in[0,1]$ at private costs $E^{2} / 2$, which enables her to learn the payoffs of all project with probability $E$, which, in a statistical sense, is independent of $e$. One of the $N$ projects is preferred by the agent. This particular project yields him private benefits $b$, and benefits $\lambda \Pi$ to the principal. The principal prefers a different project, which yields her $\Pi$, and the agent $\lambda b$, with $\lambda \in[0,1]$. Both principal and agent know a priori that such projects exist. Yet, they do not know which projects yield these payoffs. We can interpret $\lambda$ as the congruence of interests between the agent and the principal. With $\lambda=1$, their interests are aligned. With $\lambda=0$, they are diametrically opposed. For non-trivial solutions, we need $0<b<1$ and $0<\Pi<1$.

Note that only when the agent is informed, and the principal is not, the agent can implement his preferred project. If the principal is informed, she will always overrule the agent, and implement her preferred project. In this model, effort levels are strategic substitutes. When the principal exerts more effort, the probability that the manager is 
overruled, will be higher. As a result, the agent will exert less effort. Also, when the agent exerts more effort, the probability is higher that he will pick a project that is at least to some extent acceptable to the principal as well. As a result, the principal will exert less effort.

Burkart, Gromb and Panunzi (1997) use this model to study the effect of large shareholder monitoring on the value of the firm. In their model, the agent is the manager running the firm, and the principal is the large shareholder monitoring the effort of the manager. The shares not held by the large shareholder are dispersed among many minority shareholders, who do not have an individual incentive to monitor. Rather, they free ride on the effort of the large shareholder. When we interpret $\Pi$ as total security benefits, the monitoring effort of the large shareholder depends on $\alpha \Pi$, with $\alpha$ the fraction of the shares she holds. Making the additional assumption that the large shareholder can only be informed when the manager is also informed, Burkart, Gromb and Panunzi (1997) show that the optimal ownership structure has an intermediate value of $\alpha$, i.e. $0<\alpha^{*}<1$.

In this paper, we assume that the ownership of all shares is dispersed. Hence, no shareholder has an incentive to monitor. In our model, the principal is a corporate raider. She can exert effort to learn the projects that are profitable for this particular firm, and she can buy shares from shareholders at a premium $\rho>0$ when she finds such a project. In the next section, we first consider the benchmark case, in which there is no takeover threat. In subsequent sections, we take the raider into account.

\section{The Benchmark Case}

In this section, we consider the benchmark case, in which there is only a manager, and many small shareholders. The small shareholders cannot coordinate because of a free-riding problem. Each is too small to make monitoring worthwhile. Hence, in terms of the model described in the previous section, we always have $E=0$. The manager is sure not to be overruled. By exerting effort $e$, he will be informed about the payoffs of all projects with probability $e$. When he is informed, he can implement the project that yields him $b$. If not, he implements project 0 , that yields $b^{0}=0$. His expected payoff thus equals

$$
U_{m}^{B}=e b-e^{2} / 2 .
$$

Maximizing with respect to $e$ yields

$$
e^{B}=b,
$$


which is viable, since $b \in(0,1)$. The superscript $B$ reflects the equilibrium value in the benchmark model. In this benchmark case, the value of the shares, $V_{S}$, simply equals the value of the firm $V_{F}$, and we have

$$
V_{S}^{B}=V_{F}^{B}=e^{B} \lambda \Pi=\lambda b \Pi .
$$

Note that the manager is informed with probability $e^{B}=b$. If he is informed, he will implement his preferred project, which yields $\lambda \Pi$ to shareholders. If he is not informed, project 0 is implemented, which yields 0 to all parties involved. Hence, we have (3).

In the next section we consider the case in which there is a corporate raider. Initially, we assume that the raider has decided to be active in monitoring this particular firm. Under this condition, we derive the equilibrium effort of both the manager and the raider. However, it is not always rational for the raider to be active in the first place. In section 5 we derive the necessary conditions for that to be the case. In section 6 we summarize the entire model, and in section 7 we compare the benchmark case with the case of a takeover threat.

\section{The Case of a Takeover Threat}

Suppose both a manager and a raider are active. Again, by exerting effort $e$, the manager will be informed about the payoffs of all projects with probability $e$. A corporate raider exerts effort $E$ to learn all the information with probability $E$. We assume that, when the raider decides to take over the firm, she has to pay a fixed premium $\rho$ over what the value of the shares would be without a takeover, with $\rho \geq 0$. We assume $\rho$ to be constant. The raider will buy all of the shares if she takes over the firm.

If there is a takeover, the raider will implement her preferred project, which yields $\Pi$. Therefore, the expected value of the firm equals

$$
V_{F}^{R}=E \cdot \Pi+(1-E) V_{N T O},
$$

with $V_{N T O}$ the value of the shares if there is no takeover. This can be seen as follows. If the raider is informed, she will always buy all the shares in the firm, overrule the manager, and implement the project that maximizes the value of the firm, yielding $\Pi$. The probability of this happening equals $E$. When the raider is not informed, which happens with probability $(1-E)$ the value of the firm equals $V_{N T O}$.

Note that with probability $e$ the manager is informed and implements his preferred project, which yields $\lambda \Pi$ to shareholders. With probability $(1-e)$ he is not informed 
and shareholders get zero. Thus, $V_{N T O}=e \lambda \Pi$ and

$$
V_{F}^{R}=E \cdot \Pi+(1-E) e \lambda \Pi .
$$

If the raider buys the shares, she will do so at a premium $\rho$ over $V_{N T O}$. Therefore, ex ante, the total value of the shares equals

$$
\begin{aligned}
V_{S}^{R} & =E \cdot(1+\rho) \cdot e \lambda \Pi+(1-E) e \lambda \Pi \\
& =(1+E \rho) e \lambda \Pi .
\end{aligned}
$$

Note therefore that, in this model, there is a difference between the ex ante value of the shares and the expected value of the firm. In case of a takeover, shareholders receive a premium $\rho$, which allows the raider to obtain control and get more value out of the firm. Therefore, the expected value of the firm is higher than the expected value of the price shareholders receive for their shares. If this were not the case, the raider would never be able to profit from a takeover, and we would never have a takeover threat. Grossman and Hart (1980), do implicitly assume that atomistic shareholders think that, even if they personally refuse to trade, the takeover will still go through. Our approach is in line with Huddart (1993), who assumes that shareholders believe that, if they do not trade, the takeover will not succeed. ${ }^{4}$

It can be seen that our model also allows for different specifications of the takeover mechanism. For example, Grossman and Hart (1980) introduce the possibility that the raider, when successful in taking over, can dilute some maximum amount $\phi$ from the acquired firm. This gives the target's shareholders an incentive to tender their shares. When the takeover goes through regardless of their decision, then they are better off tendering at some price $p<v$, with $v$ the post-takeover value of the firm, as long as $p>v-\phi$. In our model, the post-takeover value of the firm, conditional on a takeover occurring, is $\Pi$. The price the raider pays for the shares is $(1+\rho) e \lambda \Pi$. Hence, we can interpret our model in a Grossman-Hart framework by assuming that the maximum amount of dilution equals $(1-(1+\rho) e \lambda) \Pi$.

We assume that, if there is a takeover, the manager is fired. This is in line with empirical evidence. Martin and McConnell (1991) find that management in poorly performing firms is likely to be removed when a takeover succeeds. The expected utility of the manager then equals

$$
U_{m}^{R}=e(1-E) b+E \cdot U_{F}-e^{2} / 2,
$$

where $U_{F}$ reflects the utilitity he obtains from being fired. A takeover occurs with probability $E$. If it does, the manager gets $U_{F}$. When the manager is informed and

4 See also Pagano and Röell (1998). 
the raider is not, the manager can implement his own project, which yields him $b$. This happens with probability $e(1-E)$. In all other cases, the manager simply gets zero, hence (8). Note that $U_{F}$ can be either positive or negative. When a takeover implies that the manager will be fired, becomes unemployed, or loses his reputation, then $U_{F}$ may be negative. But if the manager receives severance payments, then $U_{F}$ can be positive.

Maximizing (8) with respect to $e$ yields

$$
e=(1-E) b .
$$

If the raider is informed, which happens with probability $E$, she buys the shares at a price $(1+\rho) e \lambda \Pi$, whereas she earns $\Pi$ from controlling the firm. Her expected payoff therefore equals

$$
U_{r}^{R}=[1-(1+\rho) e \lambda] E \Pi-E^{2} / 2 .
$$

Taking the first order condition yields

$$
E=[1-(1+\rho) e \lambda] \Pi,
$$

Solving for the equilibrium values $e^{R}$ and $E^{R}$ we find ${ }^{5}$

$$
e^{R}=\frac{(1-\Pi) b}{1-(1+\rho) \lambda b \Pi} \quad E^{R}=\frac{[1-\lambda b(1+\rho) \lambda b] \Pi}{1-(1+\rho) \lambda b \Pi} .
$$

Thus, if both the manager and the corporate raider decide to exert effort, they will exert the equilibrium effort levels given by (12). However, it is not always rational for the raider to exert effort in the first place. If she decides not to do so, there is no takeover threat. In the next section, we derive the necessary conditions for the raider to exert effort.

\section{Necessary Conditions for a Takeover Threat}

For the above analysis to hold true, two conditions need to be satisfied:

1. Profitability of a takeover: if the raider is informed, she has to have an incentive to take over the firm. Thus

$$
(1+\rho) e \lambda<1 .
$$

5 In the next section we show that these values are well-defined if there is a takeover threat. 
Using (12), this reduces to ${ }^{6}$

$$
(1+\rho) \lambda b<1 .
$$

2. Managerial opportunism: if the manager is informed, he prefers to implement his own project rather than the project that maximizes shareholders' profits. Thus ${ }^{7}$

$$
(1-E) b+E U_{F}>\lambda b \text {. }
$$

Using (12), this implies

$$
U_{F}>\frac{(\Pi-1+\lambda)-(1+\rho) \lambda^{2} b \Pi}{[1-(1+\rho) \lambda b] \Pi} b .
$$

Condition (13) can be seen as follows. When the raider is informed, a takeover is profitable if the value of the firm when the raider's preferred project is implemented, $\Pi$, exceeds the costs of obtaining those shares, which is $(1+\rho) V_{N T O}$. Since $V_{N T O}=$ $e \lambda \Pi$, this implies that a necessary condition for a takeover to be profitable is $(1+\rho) e \lambda<$ 1 . The left hand side of this inequality is increasing in $e, \lambda$, and $\rho$. The intuition is as follows. The higher the effort a manager exerts, the higher the probability $e$ that he is informed, and the higher the probability that the raider cannot add much value to the firm. The higher the takeover premium $\rho$, the more expensive a takeover is. Finally, the higher the congruence of interest $\lambda$, the less value a raider can add by overruling. If (13) fails to hold, a takeover can never be profitable. In that case, a corporate raider will not have an incentive to put any effort in investigating the projects the firm can undertake. Effectively, there is no takeover threat.

The second condition can be seen as follows. For a profitable takeover, we also need that an informed manager has an incentive to implement his own preferred project rather than the project preferred by the shareholders. If that would not be the case, a raider would not be able to earn anything by taking over the firm. Assume that the manager is informed. By implementing the shareholders' preferred project, he gets $\lambda b$ with certainty. By implementing his own preferred project, he receives $b$ if the

6 Using (12), we can see that (13) implies $(1+\rho)\left[\frac{(1-\Pi) b}{1-(1+\rho) \lambda b \Pi}\right] \lambda<1$, thus $\frac{(1+\rho)(1-\Pi) \lambda b}{1-(1+\rho) \lambda b \Pi}<$ 1 , and $(1+\rho)(1-\Pi) \lambda b<1-(1+\rho) \lambda b \Pi$, hence $(1+\rho) \lambda b<1$. This condition also implies that $e^{R}, E^{R} \in(0,1)$ for all admissible parameter values. The condition for $U_{F}$ can be derived by simply plugging (12) into (15) and rearranging.

7 Of course, a manager may also choose an intermediate project that yields him $\gamma b$ and the shareholders $\eta \Pi$, with $\lambda<\gamma<1$ and $\lambda<\eta<1$. Yet, we will assume that, when the manager announces which project to implement, he knows whether or not the raider has exerted effort. It is then easy to see that it is never subgame perfect to propose such a project. 
raider is not informed, which occurs with probability $1-E$. However, if the raider is informed, which happens with probability $E$, there will be a takeover, and the manager obtains $U_{F}$. Thus, to induce the manager to choose his own preferred project when he is informed, we need (15). If that condition does not hold, and the raider has exerted effort $E$, the manager will always follow the interest of the shareholders. But given that he will do so, the raider will not exert effort in the first place and we do not have a takeover threat.

Walkling and Long (1984) show that managerial resistance to a takeover is more likely to occur when the manager perceives that his welfare may deteriorate in the presence of a takeover. This is in line with our model. The managerial opportunism condition implies that $U_{F}$ cannot be too low. When it is, the manager will resist the takeover, by simply implementing the shareholders' preferred project when he is informed. In our model this implies that a takeover threat will not exist. Given that the manager already acts in the shareholders' interest, attempting a takeover is not profitable.

\section{The Full Model}

We can now study the full model. The timing can be described as follows (see figure 1). In period $t=1$, the manager and a potential corporate raider learn the parameters of the model: $b, \Pi, \lambda, U_{F}$, and $\rho$. Based on that information, a raider decides whether or not to try to take over the company, i.e. whether or not to exert positive effort $E$. This decision is observable to the manager. Thus, the manager can observe if there is a raider actively contemplating a takeover. At $t=2$, effort is exerted. If the raider is active, the information acquiring game is the one described in section 4 . If the raider is not active, we are back to the benchmark case described in section 3. At $t=3$, the manager announces a project to implement. At $t=4$, a takeover may occur. At $t=5$, a project will be implemented. If there is no takeover, this will be the manager's proposed project, otherwise it will be the project decided by the raider. Finally, at $t=6$, payoffs are realized.

Given this description of the game, we can solve it using backward induction. As noted, sections 3 and 4 describe the two possible subgames starting in $t=2$. Given (12), we can then solve for the entire game, by checking whether (13) and (15) hold. 


\begin{tabular}{|c|c|c|c|c|c|}
\hline 1 & 2 & 3 & 4 & 5 & 6 \\
\hline 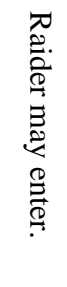 & 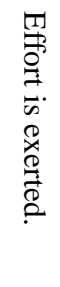 & 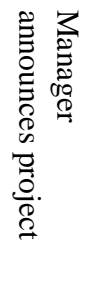 & 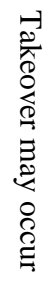 & 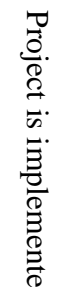 & 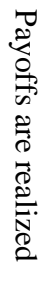 \\
\hline
\end{tabular}

Figure 6.1: Time Frame.

\section{The Effects of A Takeover Threat}

We assume here that (13) and (15) are satisfied, and the raider is active. Thus, she will be informed with probability $E^{R}$. When she is informed, she will take over the firm. Therefore $E^{R}$ also represents the probability of a takeover. We can establish the following results.

Theorem 7.1 Compared to the benchmark case, we have the following:

(a) The equilibrium effort of the raider and the equilibrium effort of the manager are strategic substitutes: $\frac{\partial e^{R}}{\partial E^{R}}, \frac{\partial E^{R}}{\partial e^{R}}<0$.

(b) The manager's equilibrium effort decreases when there is a takeover threat; $e^{B}>e^{R}$.

(c) The ex ante value of the shares with a takeover threat is always lower than the ex ante value of the shares without a takeover threat; $V_{S}^{R}<V_{S}^{B}$.

(d) For $\rho<\rho^{*}$, the expected value of the firm is higher with a takeover threat than without such a threat; $V_{F}^{R}>V_{F}^{B}$, where

$$
\rho^{*}=\frac{1+\lambda b(\lambda b \Pi-2)}{\lambda b \Pi(1-\lambda b)}
$$

Sufficient for this condition to hold is $0<\lambda b<\frac{1}{2}$.

PROOF. In Appendix.

From (a) we have that a higher effort of the manager will decrease the effort of the raider, and a higher effort of the raider will decrease the effort of the manager. When 
the manager exerts higher effort, the value of the shares is higher, which makes it less attractive to invest resources in trying to take over the firm. When a raider exerts more effort, the probability of a takeover is higher, which decreases the incentive for the manager to look for good projects. This also explains part (b).

For part (c) note that the introduction of a takeover threat has two effects. On the one hand, if there is a takeover, the shareholders earn more, since they receive more for their shares than they do without a takeover threat. This is a positive effect. On the other hand, the effort of the manager is now lower. Thus in case a takeover threat ultimately does not lead to a takeover, the ex post value of the shares is lower than in the benchmark case. This is a negative effect. In this model, the negative effect dominates.

The introduction of a takeover threat also has two contrary effects on the value of the firm. On the one hand, there is a positive effect. If there is a takeover, the raider will implement the project that yields firm value $\Pi$, which is more than the manager would have delivered. On the other hand, there is a negative effect. The threat of a takeover reduces the manager's effort. If the takeover does not occur, the ex post value of the firm is lower than it would have been in the benchmark case. When the condition in (d) is satisfied, the positive effect dominates. If not, the negative effect dominates.

In figure 2 , we have depicted the effect of a takeover on firm value in $(\lambda b, \rho)$-space, where we assume that the managerial opportunism condition is satisfied. Curve IC represents (13). On this line, this expression holds with equality, leaving the raider indifferent between monitoring and not monitoring. Thus, only in the area below IC, there is a takeover threat. The other curve represents $\rho^{*}$, as given by (17). Below this line, a takeover increases the expected value of the firm.

In area I, the value of the firm increases with a takeover threat, whereas in area II, it decreases. Note that the two curves intersect at $\lambda b=1 / 2$. Hence, $0<\lambda b<1 / 2$ is indeed sufficient to ensure an increase in firm value, as stated in the theorem. In figure 2 , we have drawn $\rho^{*}$ under the assumption that $\Pi=1 / 4$. As $\Pi$ increases, $\rho^{*}$ rotates counterclockwise around the intersection with IC. With $\Pi=0, \rho^{*}$ is vertical. With $\Pi^{*}=1$, it coincides with IC. Note that the area in which a takeover threat decreases firm value is relatively small. For that, we need that $\lambda b$ is relatively high. Then, the raider cannot add much value to the firm, which implies that the negative effect of lower managerial effort outweighs the positive effect of a value-enhancing takeover. 


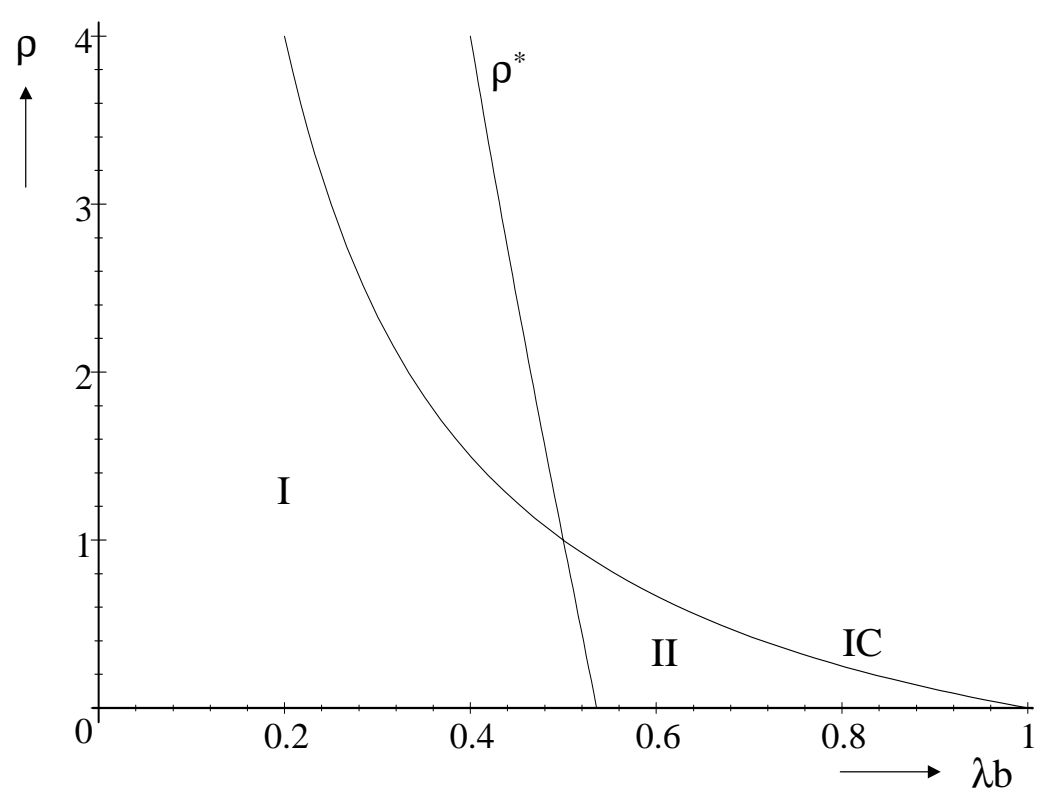

Figure 7.1: The Value Of The Firm

\section{The Effects of a Change in the Exogenous Variables}

So far, we have assumed that the variables $U_{F}$ and $\rho$ are exogenously given. In this section, we study how a change in these variables affects the outcome of the model. In particular, we look at the levels preferred by the raider and the shareholders. First note the following. One may argue that, for society as a whole, the best scenario is the one that maximizes the expected value of the firm ${ }^{8}$. When this value is maximized, the probability is the highest that the best project available will be implemented, which ultimately benefits society as a whole. Thus, in this view, a takeover threat is desirable if and only if the condition in (d) of theorem 1 is satisfied. Small shareholders always prefer a case in which there is no takeover threat. Part (c) of theorem 1 shows that without such a threat, the expected value of their shares is maximized. A corporate raider always prefers the case in which there is a takeover threat. Only in that case she can earn positive profits. Moreover, it is clear from the analysis that, when there is a takeover threat, the expected profits of the raider are always positive. Finally, the

8 See however Shleifer and Slummers (1988). 
manager may or may not prefer a takeover threat depending on whether or not the takeover poses a serious threat to his welfare.

Shareholders prefer a high takeover premium, thus a high value of $\rho$. First, a high $\rho$ makes it more likely that condition (15) fails to hold, and there will not be a takeover threat. Second, even if (15) does hold, a higher $\rho$ increases the expected value of the shares. ${ }^{9}$ Thus shareholders prefer $\rho$ as high as possible. For a similar reason, the raider prefers $\rho$ to be as small as possible. When we want to maximize firm value, the desired level of $\rho$ depends on whether or not the condition in (d) of theorem 1 is satisfied. This has an interesting implication for the desirability of takeover defenses. In our model, the natural impact of these will be to increase takeover costs, and thus the value of $\rho .^{10}$ In Continental Europe, the use of takeover defenses is prevalent (see e.g. Sudarsanam 1995). If the aim is to maximize firm value, our model suggests that a flexible view on takeover defenses is more appropriate. The policy treatment of these defenses should then be based on a 'rule-of-reason', rather than a strict rule. Indeed, if takeover defenses can be used to implement a continuous range of values for $\rho$, then (5) and (12) can be used to find the value of $\rho$ that maximizes the expected value of the firm.

Next, consider the role of $U_{F}$, which reflects the utility of the manager when he is fired. A necessary condition for a takeover threat to exist is that (16) holds. With $U_{F}$ lower than the RHS of (16), the manager always implements the shareholders' preferred policy, out of fear for a takeover. Consequently, no takeover attempt can be profitable, the raider will not monitor, and we are in the benchmark case. Therefore, this implies that shareholders prefer $U_{F}$ to be low. It is in their interest that the manager stands to lose a lot from being fired. If that is the case, there will be no takeover threat, and the expected value of their shares is higher. The raider, however,

9 From (7), $V_{S}^{R}=(1+E \rho) e \lambda \Pi$. Substituting from (12), this implies

$$
V_{S}^{R}=\left\{\frac{1-(1+\rho) \lambda b \Pi+[1-(1+\rho) \lambda b] \Pi}{[1-(1+\rho) \lambda b \Pi]^{2}}\right\} \rho(1-\Pi) \lambda b \Pi
$$

After some tedious manipulations it can be shown that this expression is increasing in $\rho$.

10 A different way to interpret anti-takeover defenses, is that they increase the costs of a takeover per se. In that interpretation, takeover defenses increase the wedge between the premium a raider has to pay, say $\rho^{+}$, and the premium the shareholders ultimately receive, say $\rho^{-}$. If such a wedge exists, it only strengthens the results in the previous section. When a takeover threat makes the shareholders worse off when $\rho^{+}=\rho^{-}$, as we assume there, then it definitely makes them worse off when the premium they receive is even lower than what the raider has to pay, and $\rho^{+}>\rho^{-}$. If takeover defenses are defined in this sense, shareholders only have an incentive to impose them as long as the increase in the wedge between $\rho^{-}$and $\rho^{+}$implies an increase in $\rho^{+}$, and they have no incentive to do so if it does not affect the premium a raider has to pay, $\rho^{+}$, but does decrease the premium they receive, $\rho^{-}$. 
prefers that $U_{F}$ is high. ${ }^{11}$ Only in that case it is profitable to try to take over the firm. This implies that, a priori, a raider wants to convince a manager that he will receive a high severance payment when the firm is taken over. It is in the raider's interest that the manager does not act in the shareholders' best interest. Only if that is the case, a takeover can be profitable, and a raider can possibly add value to the firm.

\section{Conclusion}

This paper has studied the effect of a takeover threat as a corporate control mechanism, using Aghion and Tirole's (1997) model of formal and real authority. Our paper is complementary to Burkart, Gromb and Panunzi (1997), who use the same framework to study the effect of large shareholder monitoring. The following results were obtained. First, due to a takeover threat, the effort exerted by the manager will decrease. Thus, whereas it is usually assumed that a takeover threat disciplines managers, in our model the opposite is true. Here, the manager has less incentive to exert effort in trying to learn the profitable opportunities of the firm, when he knows that he can be overruled. ${ }^{12}$ Second, it is in the shareholders' interests if there is no takeover threat. The value of their shares increases if there is a takeover, yet the mere threat of a takeover also decreases the manager's efforts, which adversely affects the value of the shares. The latter effect dominates. The value of the firm, however, is higher with a takeover threat for most parameter values. Finally, we also show that it is in the interest of the raider if the severance payments the manager receives upon being fired, are high. If that is the case, the manager stands to lose little from a takeover. Therefore, he will be less inclined to act in the shareholders' interests, which implies that a takeover can be profitable. Obviously, for the very same reason, the shareholders prefer low severance payments. If the utility the manager obtains from being fired is very low, there will not be a takeover threat, and the value of the shares will be higher.

In the real world, one often observes that the value of the shares increases when a takeover is announced. That observation is entirely consistent with our model. When

11 Note, however, that we do not take into account the fact that a positive $U_{F}$ may imply a positive monetary transfer having to be made from the raider to the manager when there is a takeover. In that case, the costs of that monetary transfer have to be subtracted from the raider's utility. This can be interpreted as a discrepancy between the premium the raider pays, and the actual premium shareholders receive. See previous footnote.

12 In the UK, the City Code on Takeovers and Mergers stipulates that, in case of a failed takeover, no new bid of the raider is allowed within twelve months (unless there is a rival bid) (see Sudarsanam, 1995, p. 85). The argument may be similar to the one in this paper; a manager will exert less effort when he knows that there is a takeover threat, thus hurting shareholders. 
a raider has decided to take over a firm, he pays a premium $\rho$ over the original value of the shares, which implies that the price at which the shares are traded on the stock market, also increases by this amount. When a takeover takes place, it makes shareholders better off. What we have shown in this paper, however, is that the threat of a takeover makes them worse off. In other words, our model predicts that share prices go up when anti-takeover provisions are taken. This is exactly what Linn and McConnell (1983) find.

In this paper, we made a host of simplifying assumptions. Yet, we believe that dropping these assumptions will considerably complicate the analysis, without adding much insight. For example, we assumed that the manager does not hold shares, and that his renumeration is in no way related to the ultimate value of the firm. Burkart, Gromb and Panunzi (1997) also make this assumption and show that relaxing it does not qualitatively change their results. We also assumed that there is only one possible raider. It is often argued that when there is a takeover attempt, rival bidders may appear. In our paper, this is not a problem. A rival bidder also has to invest in information acquisition. If she does learn the payoffs of all projects, and decides to engage in a bidding war, the shares will be bid up to $\Pi$, and takeover profits are zero. Hence, a priori, a rival bidder does not have an incentive to exert effort.

One interesting extension of our model would be the case in which the raider already owns a toehold. If she would own a fraction of, say, $\alpha_{r}$, then her utility function (10) would change. In that case, when she is informed, she would also face the choice of either taking over the firm, or simply overruling the manager. Yet, in such a setup, the incentives of all shareholders may no longer be aligned, and therefore the other shareholders may no longer have an incentive to always agree with the large shareholder, as they do in Burkart, Gromb and Panunzi (1997). If they no longer have that incentive, then overruling is not an option for the raider owning a minority fraction of the shares.

As noted earlier, our analysis complements that of Burkart, Gromb and Panunzi (1997). We look at the role of a takeover threat as a corporate control mechanism, whereas they study the role of a large shareholder. It would be interesting to consider the case in which both mechanisms are present, i.e. where there are both a corporate raider monitoring the firm and a large shareholder doing so. In that case, effective control may be lower. Since a raider can also intervene, a large shareholder has less incentive to monitor, while the opposite is also true. It is an interesting question whether, in such a framework, the results of Burkart, Gromb and Panunzi (1997) and those derived in our paper, still hold true. 


\section{Appendix}

In this appendix, we give the proof of theorem 1. Part (a) follows directly from (9) and (11). For part (b), comparing (2) and (12) we have that $e^{R}<e^{B}$ if $\frac{(1-\Pi) b}{1-(1+\rho) \lambda b \Pi}<b$. Necessary and sufficient for this to hold is exactly (14).

For part (c), suppose the opposite is true, and $V_{S}^{R}>V_{S}^{B}$. From (3) and (7) this implies

$$
\left(1+E^{R} \rho\right) e^{R} \lambda \Pi>\lambda b \Pi,
$$

thus

$$
\left(1+E^{R} \rho\right) e^{R}>b .
$$

Using (12), this implies

$$
\left\{1+\frac{[1-(1+\rho) \lambda b] \Pi}{1-(1+\rho) \lambda b \Pi} \rho\right\}\left\{\frac{(1-\Pi)}{1-(1+\rho) \lambda b \Pi}\right\}>1,
$$

thus

$$
\{1-(1+\rho) \lambda b \Pi+\rho[1-(1+\rho) \lambda b] \Pi\}(1-\Pi)>[1-(1+\rho) \lambda b \Pi]^{2},
$$

or

$$
\Pi[1-(1+\rho) \lambda b][(1+\rho) \lambda b \Pi+(1-\Pi) \rho-1]>0 .
$$

With $\Pi>0$ and, from (14), $(1+\rho) \lambda b<1$, we need

$$
(1+\rho) \lambda b>\frac{1-\rho}{\Pi}+\rho .
$$

With $\Pi \in(0,1)$ the RHS of (24) is strictly larger than one. But then (24) contradicts (14), hence $V_{S}^{R}<V_{S}^{B}$.

For part (d), substituting (9) in (5) yields

$$
V_{F}^{R}=E^{R} \cdot \Pi+\left(1-E^{R}\right)^{2} \lambda b \Pi .
$$

Using (3), we have $V_{F}^{R}>V_{F}^{B}$ whenever

$$
E^{R} \cdot \Pi+\left(1-E^{R}\right)^{2} \lambda b \Pi>\lambda b \Pi,
$$

so when

$$
\begin{gathered}
E^{R}+\left[\left(E^{R}\right)^{2}-2 E^{R}\right] \lambda b>0 \\
\Rightarrow 1+\left(E^{R}-2\right) \lambda b>0 \\
\Rightarrow E^{R}>2-\frac{1}{\lambda b} .
\end{gathered}
$$


Using (12), this implies

$$
\frac{[1-(1+\rho) \lambda b] \Pi}{1-(1+\rho) \lambda b \Pi}-\frac{2 \lambda b-1}{\lambda b}>0,
$$

hence

$$
\frac{[(1+\rho) \lambda b \Pi-\Pi \rho-2] \lambda b+1}{[1-(1+\rho) \lambda b \Pi] \lambda b}>0 .
$$

Since the denominator is positive, we need the numerator to be positive as well, which implies

$$
\lambda^{2} b^{2} \Pi-2 \lambda b+1+\lambda b \Pi \rho(\lambda b-1)>0 .
$$

Since $\lambda b-1<0$, this implies

$$
\rho<\frac{1+\lambda b(\lambda b \Pi-2)}{\lambda b \Pi(1-\lambda b)} .
$$

From (29), the condition is always satisfied with $\lambda b \in\left(0, \frac{1}{2}\right)$. This proves (d).

\section{References}

Aghion, P., And J. TiRole (1997): "Formal and Real Authority in Organizations," Journal of Political Economy, 105(1), 1-29.

Bulow, J. I., J. Geneakoplos, And P. D. Klemperer (1985): "Multimarket Oligopoly: Strategic Substitutes and Strategic Complements," Journal of Political Economy, 93, 488-511.

Burkart, M., D. Gromb, And F. PAnunzi (1997): "Large Shareholders, Monitoring, and the Value of the Firm," Quarterly Journal of Economics, 112(3), 693-728.

Grossman, S. J., And O. D. HART (1980): "Takeover Bids, the Free-Rider Problem, and the Theory of the Corporation," Bell Journal of Economics, 11, 4264.

HART, O. D. (1995): "Corporate Governance: Some Theory and Implications," Economic Journal, 105(530), 678-689.

HudDART, S. (1993): "The Effect of a Large Shareholder on Corporate Value," Management Science, 39, 1407-1421.

Kahn, C., And G. Huberman (1988): "Two-sided Uncertainty and 'Up-or-Out' Contracts," Journal of Labor Economics, 6, 423-444. 
Knoeber, C. R. (1986): "Golden Parachutes, Shark Repellents, and Hostile Tender Offers," American Economic Review, 76(1).

Linn, S. C., AND J. J. MCConnell (1983): "An Empirical Investigation of the Impact of 'Antitakeover' Amendments on Common Stock Prices," Journal of Financial Economics, 11(1-4), 361-399.

Martin, K. J., And J. J. MCConnell (1991): "Corporate Performance, Corporate Takeovers, and Management Turnover," Journal of Finance, 46(2), 671-687.

Pagano, M., AND A. RöEll (1998): "The Choice of Stock Ownership Structure: Agency Costs, Monitoring, and the Decision to Go Public," Quarterly Journal of Economics, 113(1), 187-225.

Scharfstein, D. (1988): "The Disciplinary Role of Takeovers," Review of Economic Studies, 55(2), 185-199.

ShaPIRO, C., AND J. E. STIGLITZ (1984): "Equilibrium Unemployment as a Worker Discipline Device," American Economic Review, 74(3), 433-444.

SHLEIFER, A., AND L. Summers (1988): "Breach of Trust in Hostile Takeovers," in Corporate Takeovers: Causes and Consequences, ed. by A. J. Auerbach, pp. 33-56. Chicago University Press, Chicago.

Shleifer, A., AND R. Vishny (1997): "A Survey of Corporate Governance," Journal of Finance, 52(2), 737-783.

SudARSANAM, P. S. (1995): The Essence of Mergers and Acquisitions. Prentice Hall, Hemel Hempstead.

WALKLING, R. A., AND M. S. Long (1984): "Agency Theory, Managerial Welfare, and Takeover Bid Resistance," Rand Journal of Economics, 15(1), 54-68. 